\title{
CREDIT DEFAULT SWAPS AND THE RESEARCH ON SELECTED INDICATORS IN EMERGING MARKETS
}

\section{DOI: 10.17261/Pressacademia.2019.1141}

PAP-IFC- V.10-2019(9)-p.42-49

\section{Aysun Atmisdortoglu}

Istanbul Commerce University, Faculty of Finance, Department of Financial Economics, Istanbul, Turkey. aysun.atmisdortoglu@istanbulticaret.edu.tr, ORCID: 0000-0002-0661-6506:

To cite this document

Atmisdortoglu, A.. (2019). Credit default SWAPS and the research on selected indicators in emerging markets. PressAcademia Procedia (PAP), V.10,p.42-49.

Permemant link to this document: http://doi.org/10.17261/Pressacademia.2019.1141

Copyright: Published by PressAcademia and limited licenced re-use rights only.

\begin{abstract}
Purpose- CDS premiums are an important variable which used in the measurement of country credit risk and especially in the formation of risk perception of international investors towards the country. In this study, between CDS premiums and selected economic indicators for China, Russia and Turkey from developing countries has made an empirical analysis, interaction with each other and whether the findings support other studies in the literature had investigated.

Methodology-The relationship between the CDS premiums from countries and China SHCOMP, Russia INDEXCF and Turkey XU100 stock market index and 2-year government bond interest rate and the USD exchange rate parity, by using daily data between 08.04.2010 and 15.03.2019 periods was researched with VAR analysis.

Findings- According to the empirical tests, it was concluded that the stock exchange index had the largest effect among the selected variables, whereas the exchange rate and interest rate had no significant effect.

Conclusion- In this study, offers evidence which occur the changes in CDS's standard deviation is affected from the stock market index and the effect is more in Turkey than other examined countries groups.

Keywords:Credit Default Swap (CDS), stock exchange index, government bonds interest rates, exchange rates, VAR analysis. JEL Codes: G20, G38, G39

\section{KREDi TEMERRÜT SWAPLARI VE GELIŞMEKTE OLAN ÜLKELERDE SEÇILMIŞ GÖSTERGELERÜZERINE BIR ARAŞTIRMA}

\section{ÖZET}

Amaç- CDS primleri, ülke kredi riskinin ölçülmesinde ve özellikle uluslararası yatırımcıların ülkeye yönelik risk algısının oluşmasında kullanılan önemli bir değişkendir. Bu çalışmada, gelişmekte olan ülkelerden Çin, Rusya ve Türkiye için CDS primleri ile seçilmiş ekonomik göstergeleri üzerinde ampirik bir analiz yapılarak birbirleriyle etkileşimleri ve bulguların literatürdeki diğer çalışmaları destekler nitelikte olup olmadığı araştırılmıştır.

Yöntem- Ülkelerin CDS primleri ile Çin SHCOMP, Rusya INDEXCF ve Türkiye XU100 borsa endeksleri, 2 yıllık devlet tahvili faiz oranları ve USD döviz kuru paritesi arasındaki ilişki, 08.04.2010-15.03.2019 dönem aralığındaki günlük veriler kullanılarak VAR analizi ile incelenmiştir. Bulgular- Yapılan ampirik testlerle elde edilen bulgularda, seçilmiş değişkenler arasında en büyük etkiye borsa endeksinin sahip olduğu, döviz kuru ve faiz oranının ise kayda değer bir etki taşımadığı sonucuna ulaşılmıştır.

Sonuç- Yapılan çalışma, CDS'lerin standart sapmalarında meydana gelen değişikliklerin borsa endeksinden etkilendiği ve bu etkinin incelenen ülke grupları içinde en fazla Türkiye'de olduğuna dair kanıtlar sunmaktadır.

Anahtar Kelimeler: Kredi temerrüt takası (CDS), borsa endeksi, devlet tahvilleri faiz oranı, döviz kuru, VAR analizi.

JEL Kodları:G20, G38, G39

\section{GiRiş}

Finansal piyasalarda, kredi riskinin göstergesi olarak kullanılan kredi temerrüt swapları (CDS), bir kredinin geri ödenememe riskine karşı belirli bir prim karşılığında alacaklı olan tarafı koruma altına alan finansal bir sözleşmedir. CDS kavramı 1994 yılında JP Morgan ile finansal piyasalara tanıtılmıştır. 2008 yılında yaşanan küresel krizle birlikte Lehman Brothers'ın iflası, derecelendirme kuruluşlarının verdiği kredi 
notlarının gerçeği yansıtıp yansıtmadığı sorusunu gündeme taşımış, böylece riskten korunma ihtiyacı yeni bir boyut kazanmıştır. CDS’lerin finansal piyasalarda yaygın kullanımı, kredi riskinin ölçümünde genel kabul görmüş bir gösterge haline gelmesini sağlamıştır.

CDS primleri, ülke kredi riskinin doğru teşhis edilmesinde, günlük olarak izlenebilmesinde ve yatırımcıların buna uygun doğru pozisyonu alabilmesinde önemli bir göstergedir. Yatırımcılar açısından, ülkelerde reel ekonominin performansına ilişkin önemli bir bilgi sağlamakta, özellikle gelişmekte olan ülkelerin risk primlerinin yükselmesiyle küresel finansal sisteme verebileceği zararların ve olası risklerin erken tespitine yardımcı olmaktadır. CDS primlerini etkileyen değişkenlerin belirlenmesine yönelik çalışmalar son yıllarda artış göstermiş, makroekonomik ve finansal değişkenler arasındaki ilişkiler çeşitli yöntemlerle analiz edilmeye çalışılmıştır. Bu çalışmada, gelişmekte olan ülkelerde CDS primlerinde etkisi olabilecek finansal değişkenlerin arasındaki ilişki incelenerek bu alandaki literatüre katkı sağlanmaya çalışılmıştır.

\section{LITERATÜR}

Ülkelerin CDS primlerinin finansal değişkenler ve makro ekonomik göstergeler ile olan ilişkisi konusunda literatürde farklı çalışmalar bulunmakta, risk primini etkileyen değişkenlerin tespitine ve riskin ölçülmesine yönelik yapılan çalışmalar öne çıkmaktadır. CDS primini hesaplamaya yönelik yapılan çalışmalarda, Black \& Scholes (1973), Merton (1974), Black \& Cox (1976), Longstaff \& Schwartz (1995) yapısal modelleri ortaya çıkarmışlar ve teorinin kurulmasını sağlamışlardır. Litterman \& Iben (1991) ve Jarrow \& Turnbull (1995) tarafından indirgenmiş formdaki modeller ortaya çıkarılmış ve literatüre katkı sağlanmıştır. Yapısal modellerde kredi riskinin, kaldıraç, risksiz faiz oranı ve varlık fiyatlarındaki volatiliteden etkilendiği yaklaşımı geliştirilmiştir. Jarrow, Lando \& Tumbull (1997), Duffie \& Singleton (1999), Jarrow (2001), indirgenmiş form yaklaşımını geliştirerek CDS model parametrelerini piyasadaki değerlerinden tahmin etmeye çalışmışlardır.

Pan \& Singleton (2008),CDS primleri ile VIX endeksi, 10 yıl vadeli Amerikan devlet tahvili faiz oranı, döviz kuru volatilitesi arasındaki ilişkiyi 2001-2006 dönem aralığı için regresyon analizi yaparak incelemiştir. Meksika, Türkiye ve Kore için yapılan çalışmanın sonucunda, en yüksek korelasyonun CDS primleri ile VIX endeksi arasında olduğu tespit edilmiştir.

Longstaff \& diğerleri (2011) ise, gelişmiş ve gelişmekte olan 26 ülke için CDS primleri ile küresel ve yerel makroekonomik değişkenler arasındaki ilişkiyi araştırmışlardır. 2000-2007 dönem aralığında aylık verileri kullanarak yapmış oldukları çalışmada, döviz kurları ile CDS primleri arasında pozitif yönlü bir ilişki olduğu bulunmuştur.

Liu \& Morley (2012), 2008-2010 dönem aralığında Amerika, 2005-2010 dönem aralığında ise Fransa için yapmış oldukları çalışmada, CDS spread, döviz kuru ve faiz oranı arasındaki ilişkiyi Vector Autoregressive (VAR) modeli ve Granger nedensellik testi ile incelemişlerdir. Çalışmanın sonucunda, döviz kurunun CDS üzerinde önemli bir etkisinin olduğu, 3 aylık libor faizi ile temsil edilen risksiz faiz oranının ise sınırlı bir etkiye sahip olduğunu tespit etmişlerdir. Bu çalışma, Longstaff \& arkadaşlarının yapmış oldukları çalışmaları destekler niteliktedir.

Koy (2014), CDS ve Euro-tahvil primleri arasındaki ilişkiyi, Avrupa Borç Krizi'ni de kapsayan 2009-2012 döneminde, seçilmiş 8 ülke üzerinde Granger nedensellik analizi ve birim kök testi yaparak incelemiş, Euro-tahvil priminin hesaplanmasında ABD 10 yıllık devlet tahvil getirilerini baz alarak çalışmıştır. Fransa, İtalya ve Türkiye için CDS primlerinin Euro-tahvil primlerine yön verdiğine dair kanıtlara ulaşılmış, ülkelerin CDS primlerinden Euro-tahvil primlerine doğru bir nedensellik olduğu sonucuna varılmıştır.

Yenice \& Hazar (2015), çalışmalarında gelişmekte olan ülkelerin borsa endeksi ile CDS primleri arasındaki ilişkiyi incelemiştir. Türkiye, Rusya, Arjantin, Brezilya, Endonezya, Malezya ve Çin'in 2009-2014 dönem aralığındaki günlük CDS primlerini, menkul kıymet borsa endeks kapanışı ile karşılaştırmışlardır. Yapılan bu çalışmada CDS primlerinin, ülkelerin borsa endeksleri ve döviz kuru ile bir korelasyona sahip olduğu görülmektedir.

Başarır \& Keten (2016), gelişmekte olan 12 ülkenin CDS primleri ile borsa endeksi ve döviz kuru ilişkisini incelemiş, analizlerinde $2010-2016$ dönemindeki aylık verileri kullanmışlardır. Analizin sonucunda, kısa dönem için CDS primlerinden döviz kurlarına doğru tek yönlü bir nedensellik ilişkisi, CDS primleri ile hisse senedi endeksi arasında ise çift yönlü bir nedensellik ilişkisi tespit etmişlerdir. Uzun dönem için ise herhangi bir ilişkinin tespit edilemediği sonucu bulunmuştur.

Aksoylu \& Görmüş (2018), çalışmasında, CDS primini etkilediği varsayılan finansal değişkenleri 9 ülke için incelemiş, 2005-2015 dönem aralığındaki aylık CDS primlerini etkilediği varsayılan döviz kuru, 10 yıl vadeli Amerikan devlet tahvili faiz oranı ve VIX endeksi arasında nedensellik ilişkisi olup olmadığını araştırmıştır. Analiz sonucunda, ülke CDS primleri ile finansal değişkenler arasında asimetrik nedensellik ilişkisi bulunmuştur. Literatürdeki tüm bu bahsedilen çalışmalar, CDS primleri ile borsa endeksi, döviz kuru, faiz oranı ve tahvil piyasaları arasında bir ilişki olduğunu destekler niteliktedir.

Yapılan çalışmaların çoğunluğu, CDS ile borsa endeksi arasında, diğer değişkenlere kıyasla daha güçlü bir ilişki bulunduğunu göstermekte, döviz kuru ile CDS primleri arasında da bir korelasyonun varlığına işaret etmektedir. Bu çalışmada ise, CDS primleri ile ülkelerden; Çin, Rusya ve Türkiye için borsa endeksi, döviz kuru ve faiz oranı üzerinde ampirik analizler yapılarak elde edilen bulguların literatürdeki diğer çalışmaları destekler nitelikte olup olmadığı araştırılmıştır.

\section{METODOLOJi}

Çalışmada, ülkelerin CDS primleri ile Çin SHCOMP, Rusya INDEXCF ve Türkiye XU100 borsa endeksleri, 2 yıllık devlet tahvili faiz oranları ve USD döviz kuru paritesi arasındaki ilişki, 08.04.2010-15.03.2019 dönem aralığındaki günlük veriler kullanılarak zaman serisi ile VAR analizi yapılarak incelenmiştir. Ekonometrik olarak değişkenler arasında anlamlı ilişkiler elde edilebilmesi için serilerin durağan olması 
gerektiğinden Augmented Dickey-Fuller (ADF), Phillips-Perron (PP) ve Kwiatkowski-Phillips-Schmidt-Shin (KPSS) birim kök testleri uygulanmıştır. Veri setinin tamamı Bloomberg'den alınmış olup, tüm ampirik çalışmalar E-views-8 programı kullanılarak yapılmıştır.

Veri setinin analizinde Vektör Otoregresif (VAR) modeli kullanılmış, değişkenler arasındaki kısa dönem etkileşimi ortaya koymak ve geleceğe dair öngörülerde bulunmak amaçlanmıştır. VAR modelindeki içsel değişkenlerin hata terimindeki rassal şoklara karşı tepkisinin ölçülmesi amacıyla etki-tepki fonksiyonu grafikleri kullanılmış, meydana gelen bir şokun hangi değişken tarafından açıklandığına dair varyans ayrıştırma tabloları incelenerek bulunan tüm sonuçlar her bir değişken için ayrı ayrı yorumlanmaya çalışılmıştır.

\section{AMPIRIK BULGULAR}

Veri setindeki değişkenlerin grafikleri üzerinden bir ön analiz yapıldığında, tüm ülkeler için değişkenler üzerinde pozitif ve negatif yönlü trend etkisi bulunduğu görülmüştür. Grafiklerdeki bu trend etkilerini ortadan kaldırmak için Hodrick-Prescott Filter uygulanmış ve her ülke için trend etkisinden arındırılmış veri seti elde edilmiştir. Değişkenlerin sabit bir ortalama ve sabit bir varyansa sahip olmasını sağlamak amacıyla trend etkisinden arındırılmış verilerin durağanlıkları test edilmiş, yapılan ADF, PP, KPSS durağanlık analizi birim kök testlerinin sonucunda, değişkenlerin I(0) yani durağan olduğu tespit edilmiştir.Verilerin aralarındaki ilişkinin incelenmesi amacıyla her bir ülke için VAR analizi yapılmıştır. Gecikme uzunluğu kriterine göre en uygun VAR modeli seçilerek etki-tepki grafikleri ve varyans ayrıştırma tablosunun sonuçları her ülke için ayrı ayrı incelenmiştir.

\section{1. Çin İçin Bulgular}

Çin için yapılan analizde, en uygun model VAR (9) olarak belirlenmiştir. Analizin karakteristik kökleri, modelde kullanılan değişkenlerin etkitepki grafikleri ve CDS için varyans ayrıştırma tablosu verilmiştir. Modelin kararlı olduğu ve durağanlık koşullarını yerine getirdiği görülmektedir. Etki-tepki grafikleri ile değişkenlerden birine verilen bir birimlik rassal şok sonrası bu şokun diğer değişken üzerindeki etkisi analiz edilmektedir.
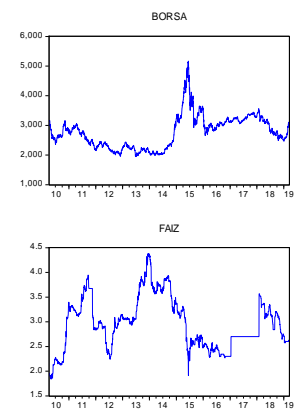

Kaynak: Bloomberg - Çin

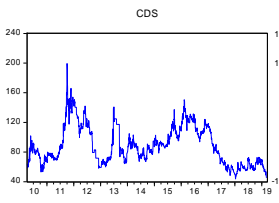

USD

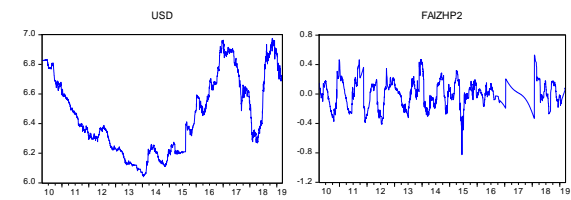

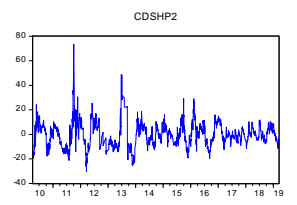

USDHP2

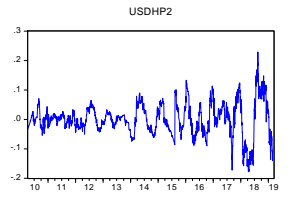

Trend etkisinden arındırılmış veri seti grafikleri

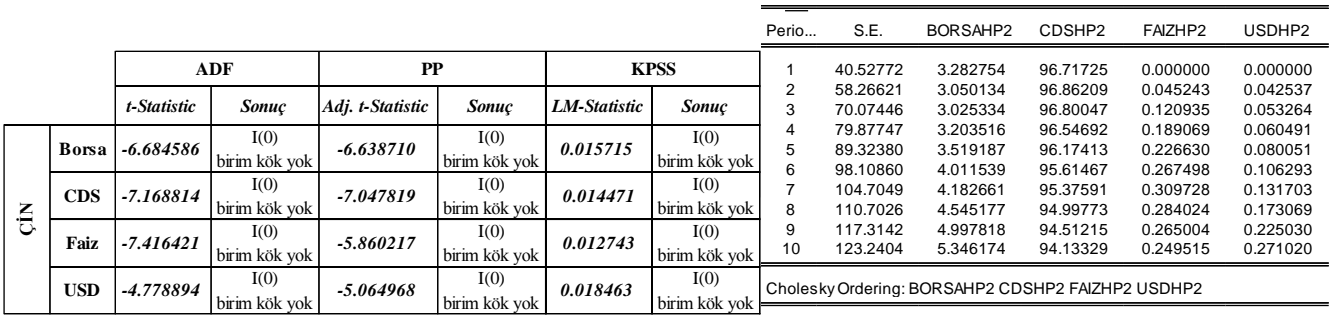

Birim kök testi sonuçları - Çin Varyans ayrıştırma tablosu - Çin

Çin için varyans ayrıştırma tablosu incelendiğinde, CDS'in standart sapmasında meydana gelen değişimlerin 1. dönemde \%96.7'sinin kendisinden kaynaklandığı, \%3.3 oranında ise Borsa endeksinin etkili olduğu, diğer değişkenlerin ise etkisinin olmadığı görülmüştür. Dönem sayısı arttıkça CDS'in kendisinden kaynaklanan etkisinin azalmaya başladığı görülmesine rağmen 10 . dönem itibari ile bu etkinin \%94 olduğu, Borsa endeksinin etkisinin ise bir miktar artarak \%5.3’e çıktığı görülmüştür, diğer değişkenlerin etkileri ise yok denecek kadar azdır fakat USD kurunun etkisi Faiz oranına göre daha fazladır.

Etki-tepki grafiklerinde ise Borsa endeksine verilen bir birimlik rassal şok, CDS üzerinde sürekli olan bir negatif etkiye sahipken, Faize verilen şok sonrası oluşan negatif etki 8 . dönem itibariyle sönümlenmektedir. USD kuruna verilen şokun ise CDS üzerinde sönümlenemeyen pozitif bir etkiye sahip olduğu görülmüştür. 


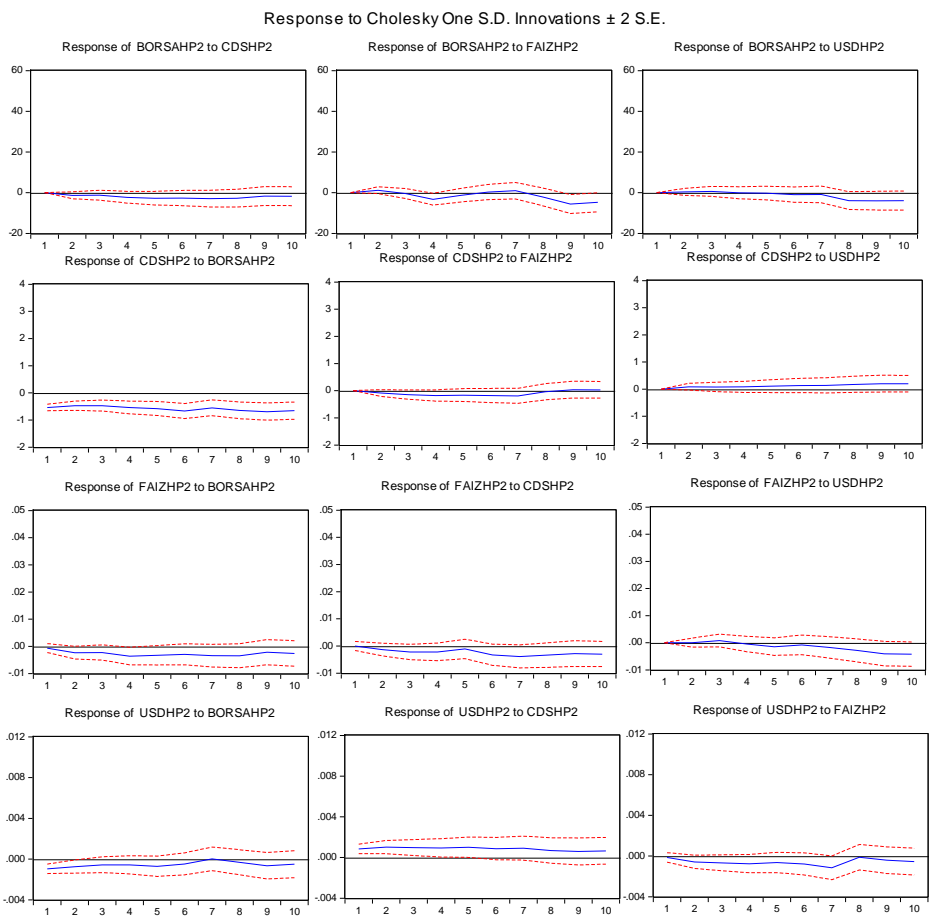

Etki - Tepki grafikleri - Çin

\subsection{Rusya İçin Bulgular}

Rusya için yapılan analizde, en uygun model VAR (8) olarak belirlenmiştir. Modelin kararlı olduğu ve durağanlık koşullarını yerine getirdiği görülmüştür.

Rusya için varyans ayrıștırma tablosu incelendiğinde, CDS'in standart sapmasında meydana gelen değișimlerin 1 . dönemde $\% 85.4$ oranında kendisinden kaynaklandığı, \%14.6 oranında ise Borsa endeksinin etkili olduğu, diğer değişkenlerin ise etkisinin olmadığı görülmüştür. Dönem sayısı arttıkça CDS'in kendisinden kaynaklanan etkisinin azalmaya başladığı ve 10. dönem itibari ile bu etkinin \%80.6 olduğu, Borsa endeksinin etkisinin ise bir miktar artarak \%18.3'e çıktığı görülmüştür, diğer değişkenlerin etkileri ise yok denecek kadar azdır fakat Faizin etkisi USD kuruna göre daha fazladır.
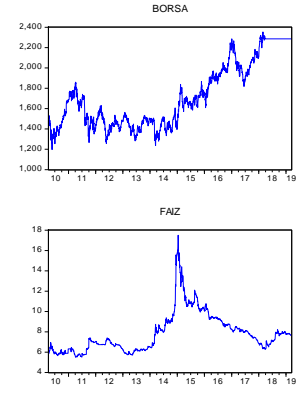

Kaynak: Bloomberg - Rusya

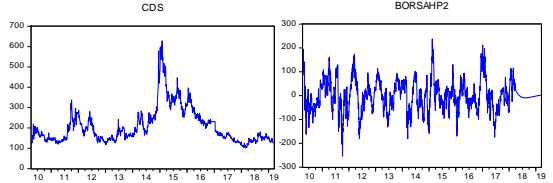

FAZHP2

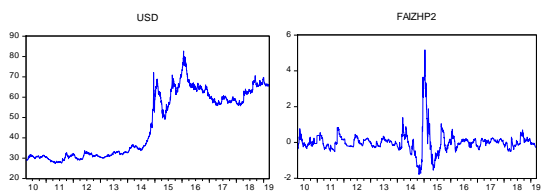

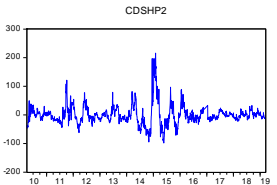

USDHP2

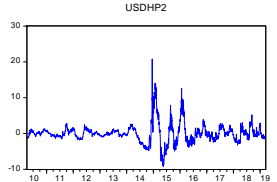

Trend etkisinden arındırılmış veri seti grafikleri 


\begin{tabular}{|c|c|c|c|c|c|c|c|c|c|c|c|c|c|}
\hline & & & & & & & \multirow{2}{*}{$\begin{array}{r}\text { Perio... } \\
\begin{array}{r}1 \\
2\end{array}\end{array}$} & \multirow{2}{*}{$\begin{array}{c}\text { S.E. } \\
18.00630 \\
25.43187\end{array}$} & \multirow{2}{*}{$\begin{array}{l}\text { BORSAHP2 } \\
\begin{array}{l}14.60226 \\
15.03533\end{array}\end{array}$} & \multirow{2}{*}{$\begin{array}{l}\text { CDSHP2 } \\
85.39774 \\
84.82847\end{array}$} & \multirow{2}{*}{$\begin{array}{l}\text { FAIZHP2 } \\
0.000000 \\
0.065282\end{array}$} & \multirow{2}{*}{$\begin{array}{l}\text { USDHP2 } \\
0.000000 \\
0.070921\end{array}$} \\
\hline & & \multicolumn{2}{|c|}{ ADF } & \multicolumn{2}{|c|}{ PP } & \multicolumn{2}{|c|}{ KPSS } & & & & & & \\
\hline & & $t$-Statistic & Sonuc & Adj. $t$-Statistic & Sonuç & LM-Statistic & Sonuç & 3 & 30.58643 & 15.01527 & 84.84619 & 0.067372 & 0.071168 \\
\hline \multirow{7}{*}{\begin{tabular}{l}
$\mathbb{3}$ \\
\multirow{2}{*}{} \\
$\approx$
\end{tabular}} & & & & & & & & & 34.62615 & 15.46019 & 84.32126 & 0.162671 & 0.055878 \\
\hline & Borsa & -7.525822 & I(0) & -7.501834 & $\mathrm{I}(0)$ & 0.015638 & $\mathrm{I}(0)$ & 5 & 37.90414 & 15.80211 & 83.94764 & 0.199522 & 0.050724 \\
\hline & & & & & birim kök yok & & birim kök yok & 6 & 40.48739 & 16.70881 & 83.06696 & 0.177641 & 0.046588 \\
\hline & CDS & -6.137726 & $\begin{array}{c}1(0) \\
\text { hirim } k \text { äk }\end{array}$ & -6.199790 & $\mathrm{I}(0)$ & 0.013066 & $\mathrm{I}(0)$ & 7 & 42.79244 & 17.09725 & 82.55385 & 0.306984 & 0.041915 \\
\hline & & & & & & & & 9 & $\begin{array}{l}44.95986 \\
46.81332\end{array}$ & 18.00598 & $\begin{array}{l}81.84986 \\
81.20389\end{array}$ & 0.584866 & $\begin{array}{l}0.113997 \\
0.205268\end{array}$ \\
\hline & Faiz & -7.161927 & birim kök yok & -5.211353 & $\begin{array}{c}1(0) \\
\text { birim kök yok }\end{array}$ & 0.012917 & birim kök yok & 10 & 48.41991 & 18.27482 & 80.57609 & 0.795679 & 0.353410 \\
\hline & USD & -6.487768 & \begin{tabular}{|c}
$\mathrm{I}(0)$ \\
birim kök yok
\end{tabular} & -6.092848 & $\begin{array}{c}\mathrm{I}(0) \\
\text { birim kök yok }\end{array}$ & 0.013661 & $\begin{array}{c}\mathrm{I}(0) \\
\text { birim kök yok }\end{array}$ & \multicolumn{6}{|c|}{ Cholesky Ordering: BORSAHP2 CDSHP2 FAIZHP2 USDHP2 } \\
\hline
\end{tabular}

Birim kök testi sonuçları - Rusya Varyans Ayrıştırma Tablosu

Etki-tepki grafiklerinde ise Borsa endeksine verilen bir birimlikrassal şok, CDS üzerinde sürekli olan bir negatif etkiye sahipken, Faize verilen şok sonrası oluşan negatif etki 5 . dönem itibariyle sönümlenerek pozitife dönmektedir. USD kuruna verilen şok ise CDS üzerinde kısa süreli negatif ve pozitif etkiler yaratmakta, sonrasında ise bu etki pozitifte sürekli hale gelmektedir.

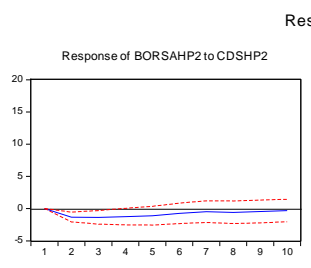

Response to Cholesky One S.D. Innovations t2 S.E.
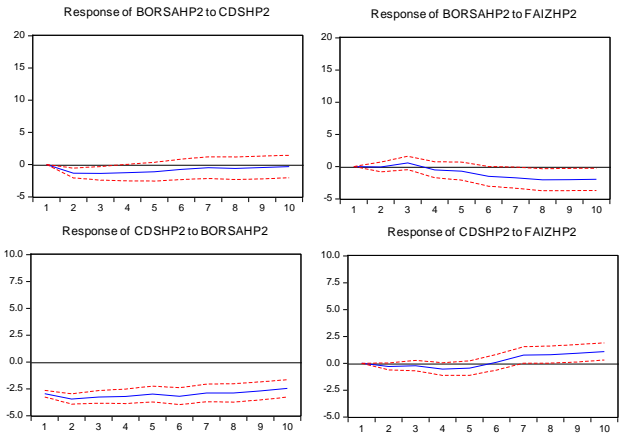

Response of BORSAHP2 to USDHP2

Response of FAIZHP2 to BORSAHP2
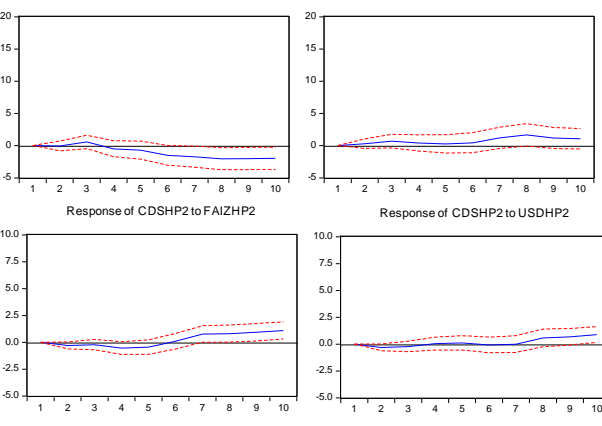

Response of CDSHP2 to USDHP2

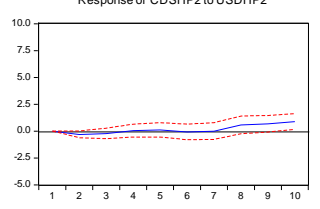

Respons of FAIZHP2 to CDSHP2
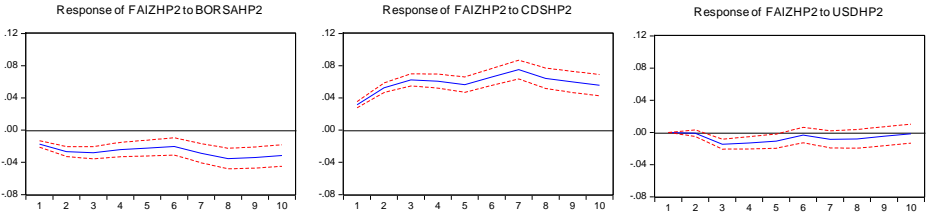

Response of USDHP2 to BORSAHP2

Response of USDHP2 to CDSHP2

Response of USDHP2 to FAIZHP2
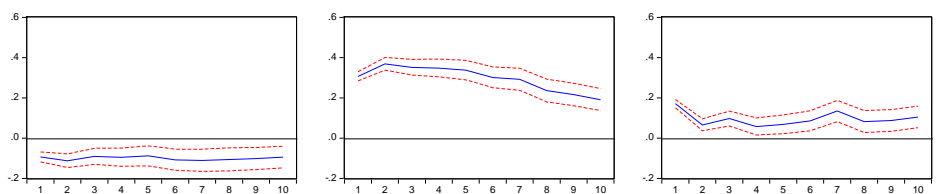

Etki - Tepki grafikleri - Rusya

\subsection{Türkiye İçin Bulgular}

Türkiye için yapılan analizde, en uygun model VAR (4) olarak belirlenmiştir. Modelin kararlı olduğu ve durağanlık koşullarını yerine getirdiği görülmüştür.

Türkiye için varyans ayrıştırma tablosu incelendiğinde, CDS'in standart sapmasında meydana gelen değişimlerin 1. dönemde \%77.6 oranında kendisinden kaynaklandığı, \%22.4 oranında ise Borsa endeksinin etkili olduğu, diğer değişkenlerin ise etkisinin olmadığı görülmüştür. Dönem sayısı arttıkça CDS'in kendisinden kaynaklanan etkisinin azalmaya başladığı ve 10 . dönem itibari ile bu etkinin \%66.8 olduğu, Borsa endeksinin etkisinin ise bir miktar artarak \%26.6'ya çıktığı görülmüştür, Faizin etkisi yok denecek kadar az olmasına rağmen USD kuru \%5.65'lik bir etkiye sahiptir. 

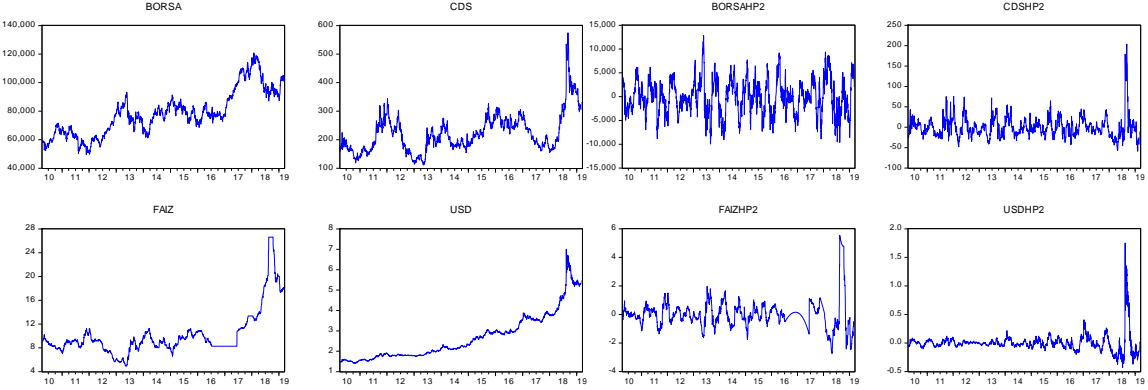

USDHP2

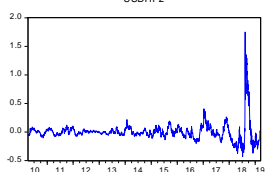

Kaynak: Bloomberg - Türkiye Trend etkisinden arındırılmış veri seti grafikleri

\begin{tabular}{|c|c|c|c|c|c|c|c|c|c|c|c|c|c|}
\hline & & & & & & & Perio... & S.E. & BORSAHP2 & CDSHP2 & FAIZHP2 & USDHP2 \\
\hline & & \multicolumn{2}{|c|}{ ADF } & \multicolumn{2}{|c|}{ PP } & \multicolumn{2}{|c|}{ KPSS } & 1 & 1041.645 & 22.37679 & 77.62321 & 0.000000 & 0.000000 \\
\hline & & $t$-Statistic & Sonuc & Adj. $t$-Statistic & Sonuc & LM-Statistic & Sonuc & $\begin{array}{l}2 \\
3\end{array}$ & $\begin{array}{l}1432.600 \\
1736.685\end{array}$ & $\begin{array}{l}22.21658 \\
22.33926\end{array}$ & $\begin{array}{l}74.95100 \\
73.39197\end{array}$ & $\begin{array}{l}0.014213 \\
0.391195\end{array}$ & $\begin{array}{l}2.818203 \\
3.877572\end{array}$ \\
\hline \multirow{7}{*}{ 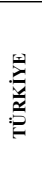 } & & & $\mathrm{I}(0)$ & & $\mathrm{I}(0)$ & & $\mathrm{I}(0)$ & 4 & 2005.362 & 22.73247 & 72.52982 & 0.541031 & 4.196684 \\
\hline & Borsa & -7.476027 & birm kök yok & -7.310030 & birim kök yok & 0.014745 & birim kök yok & 5 & 2221.190 & 23.29864 & 71.90442 & 0.590431 & 4.206513 \\
\hline & & & & & & & & 7 & 2553.253 & 24.56383 & $\begin{array}{l}71.09640 \\
70.88131\end{array}$ & $\begin{array}{l}0.655291 \\
0713995\end{array}$ & $\begin{array}{l}4.355173 \\
4641360\end{array}$ \\
\hline & $\operatorname{CDS}$ & $\mid-7.997149$ & birim kök yok & -7.448610 & birim kök yok & 0.017 & birim kök yok & 8 & 2682.959 & 25.26813 & 68.96628 & 0.783350 & $\begin{array}{l}4.641300 \\
4.982240\end{array}$ \\
\hline & Faiz & $\mid-6.603298$ & $\mathrm{I}(0)$ & 5404821 & $\mathrm{I}(0)$ & 0015531 & $\mathrm{I}(0)$ & 9 & 2794.902 & 25.96135 & 67.85922 & 0.856697 & 5.322725 \\
\hline & Falz & $\mid-6.603298$ & birim kök yok & -5.404821 & birim kök yok & 0.015531 & birim kök yok & 10 & 2892.300 & 26.63982 & 66.78234 & 0.926832 & 5.651014 \\
\hline & USD & -7.679712 & $\begin{array}{c}\mathrm{I}(0) \\
\text { hirim }\end{array}$ & -6.593121 & $\begin{array}{c}\mathrm{I}(0) \\
\text { hirim }\end{array}$ & 0.015185 & 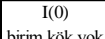 & \multicolumn{6}{|c|}{ Cholesky Ordering: BORSAHP2 CDSHP2 FAIZHP2 USDHP2 } \\
\hline
\end{tabular}

Birim kök testi sonuçları - Türkiye Varyans Ayrıştırma Tablosu

Etki-tepki grafiklerinde ise Borsa endeksine verilen bir birimlik rassal şok, CDS üzerinde sürekli olan bir negatif etkiye sahipken, Faize verilen şok sonrası oluşan negatif etki 1. dönem sonu itibariyle sürekli hale gelmektedir. USD kuruna verilen şok ise CDS üzerinde kısa süreli pozitif ve negatif etkiler yaratmakta, sonrasında ise pozitifte sürekli hale gelmektedir.

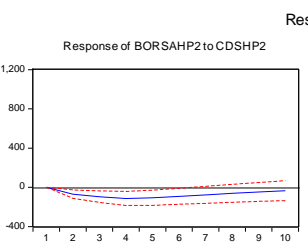

Response to Cholesky One S.D. Innovations \pm 2 S.E

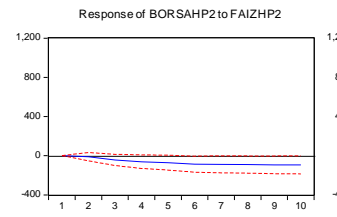

Response of BORSAHP2 to USDHP2

Response of CDSHP2 to BORSAHP2

Response of CDSHP2 to FAIZHP2
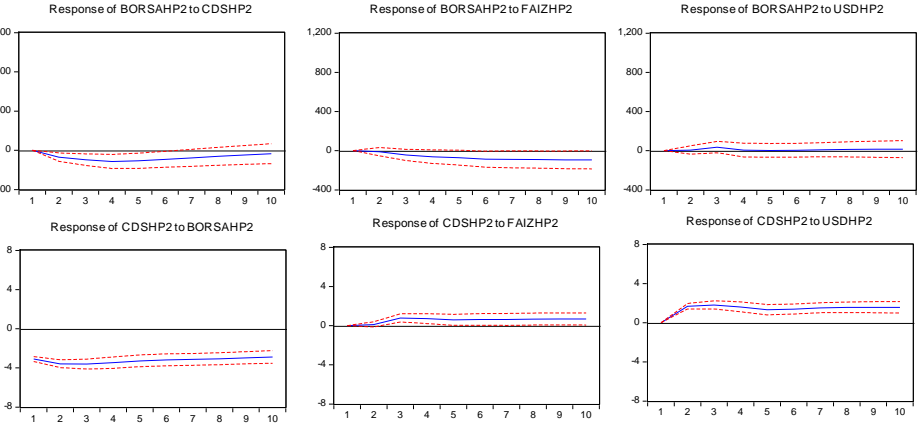

Response of FAIZHP2 to BORSAHP2

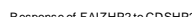

Response of FAIZHP2 to USDHP2
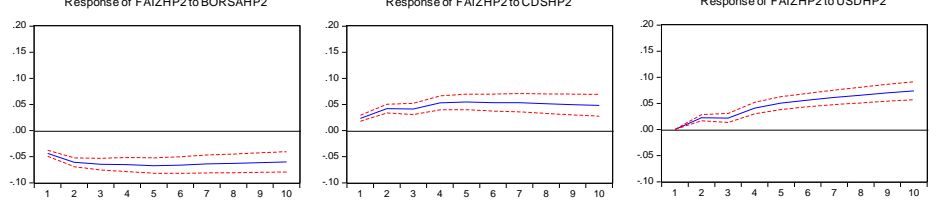

Response of USDHP2 to BORSAHP2

Response of USDHP2 to CDSHP2

Response of USDHP2 to FAIZHP2
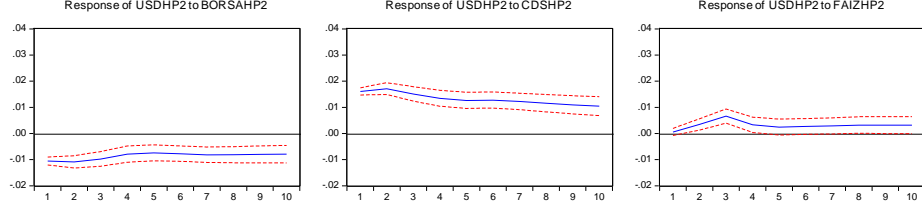

Etki - Tepki grafikleri - Türkiye 


\section{SONUÇ}

Literatürde, CDS'lerin USD kuru, Faiz ve Borsa endeksi ile aralarındaki ilişkiyi inceleyen çalışmalar mevcuttur. Bu çalışmalarda genellikle, değişkenler arasındaki kısa ve uzun dönem ilişkilerle nedensellik üzerine araştırmalar yapılmıştır. Yapılan bu çalışmanın sonucunda incelenen değişkenlerin kısa dönem etkileşiminde elde edilen bulgularda da literatürdeki önceki çalışmalara benzer ampirik kanıtlara rastlanmıştır.

CDS'in standart sapmasında meydana gelen değişimlerin sırasıyla Çin, Rusya ve Türkiye'de en fazla kendisinden kaynaklandığı, Çin'de bu oran \%96.7 ile \%94 arasında iken Rusya'da \%85.4 ile \%80.6 arasında, Türkiye'de ise \%77.6 ile \%66.8 arasında olduğu görülmüştür. CDS'in standart sapmasında meydana gelen değişimler üzerinde ikinci sıradaki etkiyi Borsa endeksinin aldığı ve dönemler arttıkça etkinin de artış yönünde olduğu tespit edilmiştir. Bu etkinin incelenen ülke grupları içinde \%22.4 ile \%26.6 arasında en fazla Türkiye'de olduğu görülmüş olup, Rusya'da \%14.6 ile \%18.3 arasında, Çin'de ise \%3.3 ile \%5.3 arasındadır.

Yapılan ampirik testlerle elde edilen bu bulgular neticesinde, seçilmiş değişkenler arasında en büyük etkiye Borsa endeksinin sahip olduğu, döviz kuru ve faiz oranının ise borsanın etkisine kıyasla CDS üzerinde kayda değer bir oranda etkisinin olmadığı sonucuna ulaşılmıştır. Bulgular, Pan \& Singleton (2008), Longstaff \& diğerleri (2011), Başarır \& Keten (2016) çalışmalarını da doğrular niteliktedir.

Faiz ve USD kurunun CDS üzerindeki etkisi incelendiğinde ise Çin'de USD kuru etkisinin Faiz oranına göre daha fazla olduğu, Rusya'da ise Faiz oranının etkisinin USD kuruna göre daha fazla olduğu görülmüştür. Türkiye'de ise Faiz oranının etkisi yok denecek kadar az olmasına rağmen USD kurunun etkisinin olduğu tespit edilmiştir.Yapılan analizdeki bulgular, Longstaff \& diğerleri (2011), Yenice \& Hazar (2015), Liu \& Morley (2012), Başarır \& Keten (2016)'in çalışmalarını Türkiye için doğrular niteliktedir fakat incelenen diğer ülkeler için faiz oranı etkisinin de önemli olduğuna dair kanıtlara ulaşılmıştır.

\section{KAYNAKLAR}

Aksoylu, E., Görmüş, Ş. (2018). Gelişmekte olan ülkelerde ülke riski göstergesi olarak kredi temerrüt swapları: asimetrik nedensellik yöntemi. Ekonomik ve Sosyal Araştırmalar Dergisi, 14 (1).

Başarır, Ç., Keten, M. (2016). Gelişmekte olan ülkelerin CDS primleri ile hisse senetleri ve döviz kurları arasındaki kointegrasyon ilişkisi. Mehmet Akif Ersoy Üniversitesi Sosyal Bilimler Enstitüsü Dergisi, 8 (15).

Beirne, J., Fratzscher, M. (2013). The pricing of sovereign risk and contagion during the European sovereign debt crisis. Journal of International Money and Finance, 34, 60-82.

Black, F., Scholes, M. (1973). The pricing of options and corporate liabilities. Journal of Political Economy 81 (3), $637-654$.

Black, F., Cox, J. C. (1976). Valuing corporate securities: some effects of bond indenture provisions. Journal of Finance, 31, 351-367.

Brooks, C. (2008). Introductory econometrics for finance (2. bs.). New York, Cambridge University Press.

Can, H., Paskaleva, M. (2017). Macroeconomic determinants of CDS: the case of Europe. New Knowledge Journal of Science, 6 (3).

Fontana, A., Scheicher, M. (2016). An analysis of euro area sovereign CDS and their relation with government bonds. Journal of Banking \& Finance, 62, 126-140

Grammatikos, T., Vermeulen, R. (2012). Transmission of the financial and sovereign debt crises to the EMU: stock prices. CDS Spreads and Exchange Rates.

Hammoudeh, S., Sarı, R. (2011). Financial CDS, stock market and interest rates: which drives which?. North American Journal of Economics and Finance, (22), 257-276.

Hui, C. H., Wing, Fong T. P. (2015). Price cointegration between sovereign CDS and currency option markets in the financial crises of 20072013. International Review of Economics and Finance, 40, 174-190.

Hull, J. C. (2012). Options, futures and other derivatives (8. bs.). New Jersey, Prentice Hall.

Kargı, B. (2014). Credit default swap (CDS) spreads: the analysis of time series for the integration with the interest rates and the growth in Turkish economy. Montenegrin Journal of Economics, 10 (1), 59-66.

Koy, A. (2014). Kredi temerrüt swapları ve tahvil primleri üzerine ampirik bir çalışma. International Review of Economics and Management, 2, 63-79.

Liu, Y., Morley, B. (2012). Sovereign credit default swaps and the macroeconomy. Applied Economics Letters, 19, 129-132.

Liu, Y., Morley, B. (2013). Sovereign credit ratings, the macroeconomy and credit default swap spread. Brussels Economic Review Cahiers Economiques De Bruxelles, 56 (3/4), 335-348.

Longstaff, F.A., Schwartz, E. (1995). Valuing credit derivatives. Journal of Fixed Income 5, 6-12.

Longstaff, F.A. (2005). Borrower credit and the valuation of mortgage backed securities. Real Estate Economics, 33, 619-661. 
Longstaff, F.A., Pan, J., Pedersen, L.H., Singleton, K.J. (2011). How sovereign is sovereign credit risk?. American Economic Journal: Macroeconomics 3 (2), 75-103.

Merton, R. (1973). Theory of rational option pricing. Bell Journal of Economics, 141-183.

Norden, L., Weber, M. (2004). Informational efficiency of credit default swap and stock markets: the impact of credit rating announcements. Journal of Banking \& Finance, 28 (11), 2813-2843.

Norden, L., Weber, M. (2009). The co-movement of credit default swap, bond and stock markets: an empirical analysis. European Financial Management, 15 (3), 529-562.

Pan, J., Singleton, K. J. (2008). Default and recovery implicit in the term structure of sovereign CDS spreads. The Journal of Finance, 63 , 2345-2384.

Rachev, S.T., Mittnik, S., Fabozzi, F.J., Focardi, S.M., Jasic, T. (2007). Financial econometrics from basics to advanced modeling techniques. New York, John Wiley \& Sons Inc.

Yenice, S., Hazar, A. (2015). A study for the interaction between risk premiums and stock exchange in developing countries. Journal of Economics, Finance and Accounting, (2).

Zhu, H. (2006). An empirical comparison of credit spreads between the bond market and the credit default swap market. Journal of Financial Services Research, 29 (3), 211-235.

Zivot, E., Wang, J. (2006). Modelling financial time series with S-Plus (2. bs.). Washington, Washington University. 